\title{
Dielectric Properties of Azo Polymers: Effect of the Push-Pull Azo Chromophores
}

\author{
Xuan Zhang, ${ }^{1}$ Ziqi Wen, ${ }^{1}$ Hongxing Zhang, ${ }^{2}$ Weihua Han, ${ }^{2}$ Jinyi Ma, \\ Renbo Wei $\left(\mathbb{D},{ }^{2}\right.$ and Xiufu Hua $(\mathbb{D})^{3}$ \\ ${ }^{1}$ Department of Chemical Engineering, Northwest University, Xian 710069, China \\ ${ }^{2}$ Center for Applied Chemistry, University of Electronic Science and Technology of China, Chengdu 610054, China \\ ${ }^{3}$ Department of Scientific Research and Development, Tsinghua University, Beijing 100084, China
}

Correspondence should be addressed to Renbo Wei; weirb10@uestc.edu.cn and Xiufu Hua; huaxf@mail.tsinghua.edu.cn

Received 12 December 2017; Accepted 16 January 2018; Published 12 February 2018

Academic Editor: Hossein Roghani-Mamaqani

Copyright (c) 2018 Xuan Zhang et al. This is an open access article distributed under the Creative Commons Attribution License, which permits unrestricted use, distribution, and reproduction in any medium, provided the original work is properly cited.

\begin{abstract}
The relationship between the structure and the dielectric properties of the azo polymers was studied. Four azo polymers were synthesized through the azo-coupling reaction between the same precursor (PAZ) and diazonium salts of 4-aminobenzoic acid ethyl ester, 4-aminobenzonitrile, 4-nitroaniline, and 2-amino-5-nitrothiazole, respectively. The precursor and azo polymers were characterized by ${ }^{1} \mathrm{H}$ NMR, FT-IR, UV-vis, GPC, and DSC. The dielectric constant and dielectric loss of the samples were measured in the frequency range of $100 \mathrm{~Hz}-200 \mathrm{kHz}$. Due to the existence of the azo chromophores, the dielectric constant of the azo polymers increases compared with that of the precursor. In addition, the dielectric constant of the azo polymers increases with the increase of the polarity of the azo chromophores. A random copolymer (PAZ-NT-PAZ) composed of the azo polymer PAZ-NT and the precursor PAZ was also prepared to investigate the content of the azo chromophores on the dielectric properties of the azo polymers. It showed that the dielectric constant increases with the increase of the azo chromophores. The results show that the dielectric constant of this kind of azo polymers can be controlled by changing the structures and contents of azo chromophores during the preparation process.
\end{abstract}

\section{Introduction}

Dielectric materials which can be used to control and/or store charge and electric energy play an important strategic role in modern electronic and power systems. With the rapid development of the electric industry, dielectric materials have been intensively investigated in recent years owing to their fascinating properties and potential applications in electronic devices $[1,2]$. Up to now, the most used dielectric materials are the inorganic dielectric materials (inorganic piezoelectric ceramic materials) including titanium dioxide [3], calcium titanate [4], magnesium titanate [5], barium titanate [6,7], mica [8], boron nitride [9], aluminum oxide [10], among others. Although the inorganic dielectric materials usually show higher dielectric constant which is critical for its application, its fragility and high processing temperature limit its further application. With the development of information technology and microelectronics industry, the miniaturization, integration, and intellectualization of new devices such as dielectric substrate, dielectric antenna, and embedded thin film capacitor require that the dielectric materials not only show excellent dielectric properties but also have good mechanical properties and processing properties $[11,12]$.

The dielectric materials including the polypropylene (PP) [13], biaxially oriented polypropylene (BOPP) [14], polyethylene terephthalate (PET) [15], poly(vinylidene fluoride) (PVDF) $[16,17]$, and polyarylene ether nitrile (PEN) [18-22], among others, have recently attracted considerable attention from the material research community. In comparing with the inorganic dielectric materials, the dielectric materials especially the polymeric dielectric materials exhibit the advantages of low intrinsic density, excellent 
<smiles>CN(C)CC(O)COc1ccc(C(C)(C)c2ccc(OCC(O)CC(C)(C)CC(C)(C)c3ccc(N)cc3)cc2)cc1</smiles><smiles>[Y]N=Nc1ccc(N(C)CC(O)COc2ccc(C(C)(C)c3ccc(OCC(O)CC(C)(C)C(C)N)cc3)cc2)cc1</smiles>

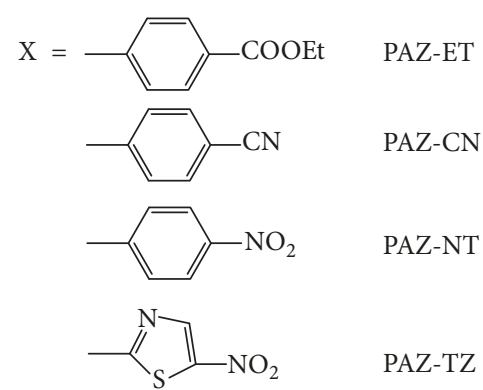

FIgURE 1: Synthetic route for the azo polymers.

performance, easy processing, long serving life, and even recyclability [11]. However, pure polymer material suffers from the defect of low dielectric constant [21, 22]. As a result, preparing polymer-based composite which combines the advantages of polymer material and inorganic additive has been intensively investigated in recent years [23-25]. However, the addition of the inorganic additive also results in the increment of the dielectric loss of the system $[23,24]$. Another method to improve the dielectric constant of a polymer is to increase the polar groups in the polymer, as the dielectric constant indicates how easily a material can become polarized by imposition of an electric field on an insulator [21]. For example, PEN is widely used as dielectric materials for its high dielectric constant attributing to the polar cyano groups as the side-chains on the backbone [18-21]. PVDF is also one of the mostly used dielectric materials due to its high dielectric constant resulting from the asymmetrical fluorine $[16,17]$.

Azobenzene as a functional group has been widely used to design materials with photoresponsive property [26-29]. When irradiated with appropriate light, polymers containing azobenzene groups (azo polymers for short) will show different photoresponsive properties attributing to the reversible photoinduced trans-cis isomerization of the azo chromophores [30-33]. The photoresponsive properties and applications of azo polymers include photoinduced birefringence [34], dichroism [35], surface-relief-grating [36, 37], spontaneous surface pattern [38], and contraction and bending [39-41], among others. On the other hand, the azobenzene, usually as organic dyes, possesses conjugated molecular structures with large dipole moments resulting from the terminal electron donors and acceptors. Consequently, the azobenzene can be potentially used as the polar groups to fabricate organic dielectric materials [42].
In addition, resulting from the high efficiency of the azocoupling reaction, azo polymers containing different pushpull azo chromophores can be easily obtained [43-46]. As a result, the relationship between the structure and the dielectric properties of the azo polymers can be systematically investigated.

In this work, the relationship between the structure and the dielectric properties of the azo polymers was studied. An epoxy-based precursor was firstly synthesized by condensation polymerization from bisphenol A diglycidyl ether and aniline. Then, a series of azo polymers with different substituents at $4^{\prime}$-positions of the azobenzene units were prepared by the azo-coupling reaction from that precursor. The azo polymers were characterized by ${ }^{1} \mathrm{H}$ NMR, FT-IR, UV-vis, GPC, and DSC. The influences of the molecular structures on the dielectric properties of the azo polymers were investigated in detail.

\section{Experimental Section}

2.1. Materials. Bisphenol A diglycidyl ether (80\%), aniline (99\%), 2-amino-5-nitrothiazole (97\%), and 4-aminobenzonitrile (98\%) were purchased from Alfa Aesar, Tianjin, China. 4-Aminobenzoic acid ethyl ester (98\%) and 4-nitroaniline (98\%) were purchased from J\&K chemicals, Beijing, China. Tetrahydrofuran (THF) was purified by distillation with sodium and benzophenone. Deionized water was obtained from a Milli-Q water purification system. All of the other reagents and solvents were purchased commercially and used as received without further purification.

2.2. PAZ. As shown in Figure 1, the precursor polymer (PAZ) and the azo polymers (PAZ-R, R = ET, CN, NT, and TZ) were prepared according to the literature [37]. Bisphenol A 
diglycidyl ether $(18.8 \mathrm{~g}, 0.1 \mathrm{~mol})$ and aniline $(4.7 \mathrm{~g}, 0.05 \mathrm{~mol})$ were homogeneously mixed before polymerizing and then polymerized at $110^{\circ} \mathrm{C}$ for $20 \mathrm{~h}$. The production was dissolved in a $\mathrm{CHCl}_{3} / \mathrm{CH}_{3} \mathrm{OH}$ solvent mixture $(4: 1,200 \mathrm{~mL})$ followed by precipitation in $800 \mathrm{~mL}$ of acetone. The polymer was collected by filtration and dried under vacuum for $24 \mathrm{~h} .{ }^{1} \mathrm{H}$ NMR (DMSO- $\left.d_{6}\right): \delta=7.07(6 \mathrm{H}, \mathrm{d}), 6.82(4 \mathrm{H}, \mathrm{d}), 6.72(2 \mathrm{H}, \mathrm{d})$, $6.54(1 \mathrm{H}, \mathrm{m}), 5.27(1 \mathrm{H}, \mathrm{d}), 5.18(1 \mathrm{H}, \mathrm{d}), 4.03(2 \mathrm{H}, \mathrm{m}), 3.87(4 \mathrm{H}$, s), 3.34-3.75 $(4 \mathrm{H}, \mathrm{m})$, and $1.55(6 \mathrm{H}, \mathrm{s})$. FT-IR $\left(\mathrm{KBr}, \mathrm{cm}^{-1}\right)$ : $3365(\mathrm{O}-\mathrm{H}, \mathrm{s}), 2963$ and 2926 (C-H, m), 1600, 1508, and 1459 (Benz. ring, s), and 1247 (C-O, s). GPC: $M_{n}=2.47 \times 10^{4}$ and $M_{w} / M_{n}=1.69$. DSC: $T_{g}=89.8^{\circ} \mathrm{C}$.

2.3. PAZ-CN. According to the literature [37], PAZ (1.3 g, $3 \mathrm{mmol})$ was dissolved in DMF $(150 \mathrm{~mL})$ at $0^{\circ} \mathrm{C}$. A diazonium salt of 4 -aminobenzonitrile was prepared by adding an aqueous solution of sodium nitrite $(0.37 \mathrm{~g}, 5.5 \mathrm{mmol}$ in $3 \mathrm{~mL}$ of water) into a solution of 4 -aminobenzonitrile $(0.54 \mathrm{~g}$, $4.5 \mathrm{mmol}$ ) in a homogeneous mixture of $1.3 \mathrm{~mL}$ of sulfuric acid and $18 \mathrm{~mL}$ of glacial acetic acid. The mixture was stirred at $0^{\circ} \mathrm{C}$ for $30 \mathrm{~min}$ and then was added dropwise into the solution of PAZ. The solution was stirred at $0^{\circ} \mathrm{C}$ for another $12 \mathrm{~h}$. Then the solution was poured into plenty of water and the precipitate was collected and dried afterwards. The product was dissolved in $60 \mathrm{~mL}$ THF and precipitated into $600 \mathrm{~mL}$ petroleum ether. The final product was dried in vacuum at $70^{\circ} \mathrm{C}$ for $24 \mathrm{~h} .{ }^{1} \mathrm{H}$ NMR (DMSO- $\left.d_{6}\right): \delta=7.93(2 \mathrm{H}$, d), $7.83(2 \mathrm{H}, \mathrm{d}), 7.75(2 \mathrm{H}, \mathrm{d}), 7.06(4 \mathrm{H}, \mathrm{d}), 6.91(2 \mathrm{H}, \mathrm{d}), 6.84$ $(4 \mathrm{H}, \mathrm{d}), 5.40(\mathrm{H}, \mathrm{d}), 5.29(\mathrm{H}, \mathrm{d}), 4.12(2 \mathrm{H}, \mathrm{m}), 3.70-4.01(6 \mathrm{H}$, $\mathrm{m})$, 3.41-3.70 $(2 \mathrm{H}, \mathrm{m})$, and $1.54(6 \mathrm{H}, \mathrm{s})$. FT-IR $\left(\mathrm{KBr}, \mathrm{cm}^{-1}\right)$ : $3400(\mathrm{O}-\mathrm{H}, \mathrm{s}), 2963$ and $2927(\mathrm{C}-\mathrm{H}, \mathrm{m}), 2227(\mathrm{C} \equiv \mathrm{N}, \mathrm{m}), 1600$ and 1510 (Benz. ring, s), $1384(-\mathrm{N}=\mathrm{N}-, \mathrm{m})$, and 1247 (C-O, s). GPC: $M_{n}=2.96 \times 10^{4}$ and $M_{w} / M_{n}=1.82$. UV-vis: $\lambda_{\max }=$ $452 \mathrm{~nm}$. DSC: $T_{g}=120.5^{\circ} \mathrm{C}$.

2.4. PAZ-ET. PAZ-ET was similarly prepared as mentioned for PAZ-CN. FT-IR $\left(\mathrm{KBr}, \mathrm{cm}^{-1}\right)$ : 3397 (O-H, s), 2963 and 2927 (C-H, m), $1713(\mathrm{C}=\mathrm{O}, \mathrm{s}), 1599,1510$, and 1460 (Benz. ring, s), $1386(-\mathrm{N}=\mathrm{N}-, \mathrm{m})$, and $1241(\mathrm{C}-\mathrm{O}, \mathrm{s}) .{ }^{1} \mathrm{H}$ NMR (DMSO- $\left.d_{6}\right)$ : $\delta=8.06(2 \mathrm{H}, \mathrm{d}), 7.82(2 \mathrm{H}, \mathrm{d}), 7.74(2 \mathrm{H}, \mathrm{d}), 7.07(4 \mathrm{H}, \mathrm{d}), 6.90$ $(2 \mathrm{H}, \mathrm{d}), 6.84(4 \mathrm{H}, \mathrm{d}), 5.40(\mathrm{H}, \mathrm{d}), 5.29(\mathrm{H}, \mathrm{d}), 4.30(2 \mathrm{H}, \mathrm{t}), 4.12$ $(2 \mathrm{H}, \mathrm{m}), 3.70-4.00(6 \mathrm{H}, \mathrm{m}), 3.40-3.70(2 \mathrm{H}, \mathrm{m}), 1.54(6 \mathrm{H}, \mathrm{s})$, and $1.30(3 \mathrm{H}, \mathrm{d})$. GPC: $M_{n}=3.16 \times 10^{4}$ and $M_{w} / M_{n}=1.88$. UV-vis: $\lambda_{\max }=438 \mathrm{~nm}$. DSC: $T_{g}=112.7^{\circ} \mathrm{C}$.

2.5. PAZ-NT. PAZ-NT was similarly prepared as mentioned for PAZ-CN. FT-IR $\left(\mathrm{KBr}, \mathrm{cm}^{-1}\right): 3420(\mathrm{O}-\mathrm{H}, \mathrm{s}), 2963$ and 2927 (C-H, m), 1602 and 1510 (Benz. ring, s), $1384(-\mathrm{N}=\mathrm{N}-$, $\mathrm{m})$, and $1243(\mathrm{C}-\mathrm{O}, \mathrm{s}) .{ }^{1} \mathrm{H}$ NMR (DMSO- $\left.d_{6}\right): \delta=8: 32(2 \mathrm{H}$, d), $7.88(2 \mathrm{H}, \mathrm{d}), 7.75(2 \mathrm{H}, \mathrm{d}), 7.06(4 \mathrm{H}, \mathrm{d}), 6.90(2 \mathrm{H}, \mathrm{d}), 6.82$ $(4 \mathrm{H}, \mathrm{d}), 5.40(\mathrm{H}, \mathrm{d}), 5.29(\mathrm{H}, \mathrm{d}), 4.12(2 \mathrm{H}, \mathrm{m}), 3.71-4.00(6 \mathrm{H}$, $\mathrm{m}), 3.41-3.66(2 \mathrm{H}, \mathrm{m})$, and $1.55(6 \mathrm{H}, \mathrm{s})$. GPC: $M_{n}=2.91 \times$ $10^{4}$ and $M_{w} / M_{n}=1.78$. UV-vis: $\lambda_{\max }=482 \mathrm{~nm}$. DSC: $T_{g}=$ $124.8^{\circ} \mathrm{C}$.
2.6. PAZ-TZ. PAZ-TZ was prepared according to the literature [44], nitrososulfuric acid was prepared by carefully adding sodium nitrite $(0.21 \mathrm{~g}, 3 \mathrm{mmol})$ to $2 \mathrm{~mL}$ of sulfuric acid at $65^{\circ} \mathrm{C}$ while stirring. The resulting solution was cooled in an ice bath and diluted with $5 \mathrm{~mL}$ of acetic acid. A diazonium salt of 2-amino-5-nitrothiazole was prepared by adding the solid of 2-amino-5-nitrothiazole $(0.36 \mathrm{~g}, 2.5 \mathrm{mmol})$ directly into the above nitrososulfuric acid solution and stirred at $0^{\circ} \mathrm{C}$ at least for $2 \mathrm{~h}$. The diazonium salt solution was added dropwise into a solution of PAZ $(0.86 \mathrm{~g}, 2 \mathrm{mmol})$ in $100 \mathrm{~mL}$ DMF at $0^{\circ} \mathrm{C}$. The solution was stirred at $0^{\circ} \mathrm{C}$ for another $12 \mathrm{~h}$. After precipitation of the above solution in water and being dried for $12 \mathrm{~h}, \mathrm{PAZ}-\mathrm{TZ}$ was purified by dissolving in THF and precipitating in petroleum ether and then dried in vacuum for $24 \mathrm{~h}$. FT-IR $\left(\mathrm{KBr}, \mathrm{cm}^{-1}\right): 3441(\mathrm{O}-\mathrm{H}, \mathrm{s}), 3045,1460$, and 753 (thiazole, m), 2964 and 2870 (C-H, m), 1601 and 1508 (Benz. ring, s), $1353(-\mathrm{N}=\mathrm{N}-, \mathrm{m}), 1340(\mathrm{~N}=\mathrm{O}, \mathrm{m})$, and $1240(\mathrm{C}-\mathrm{O}$, s). ${ }^{1} \mathrm{H}$ NMR (DMSO- $\left.d_{6}\right): \delta=8.26(1 \mathrm{H}, \mathrm{s}), 7.80(2 \mathrm{H}, \mathrm{d}), 7.10$ $(6 \mathrm{H}, \mathrm{d}), 6.86(4 \mathrm{H}, \mathrm{d}), 5.40(\mathrm{H}, \mathrm{d}), 5.29(\mathrm{H}, \mathrm{d}), 4.17(2 \mathrm{H}, \mathrm{m})$, $3.70-4.00(6 \mathrm{H}, \mathrm{m}), 3.40-3.65(2 \mathrm{H}, \mathrm{m})$, and $1.57(6 \mathrm{H}, \mathrm{s})$. GPC: $M_{n}=3.01 \times 10^{4}$ and $M_{w} / M_{n}=1.84$. UV-vis: $\lambda_{\max }=572 \mathrm{~nm}$. DSC: $T_{g}=138.7^{\circ} \mathrm{C}$.

2.7. PAZ-NT-PAZ. PAZ-NT-PAZ would be the random copolymer of PAZ and PAZ-NT, and it was similarly prepared as mentioned for PAZ-NT. However, only $30 \%$ of the diazonium salt as preparing PAZ-NT was added to the PAZ solution. ${ }^{1}$ H NMR (DMSO- $d_{6}$ ): $\delta=8.34$ (d), 7.89 (d), $7.74(\mathrm{~d})$, 7.09 (d), 6.90 (d), 6.82 (d), 6.73 (d), 6.54 (m), 5.40 (d), 5.32 (m), $5.18(\mathrm{~d}), 4.12(\mathrm{~m}), 4.05(\mathrm{~m}), 3.87(\mathrm{~s}), 3.34-3.75(\mathrm{~m})$, and 1.55 (s). FT-IR $\left(\mathrm{KBr}, \mathrm{cm}^{-1}\right)$ : 3365 (O-H, s), 2963 and 2927 (C$\mathrm{H}, \mathrm{m}), 1713(\mathrm{C}=\mathrm{O}, \mathrm{s}), 1600,1508$, and 1459 (Benz. ring, s), 1384 $(-\mathrm{N}=\mathrm{N}-, \mathrm{m})$, and $1243(\mathrm{C}-\mathrm{O}, \mathrm{s})$. GPC: $M_{n}=2.72 \times 10^{4}$ and $M_{w} / M_{n}=1.75$. UV-vis: $\lambda_{\max }=482 \mathrm{~nm}$. DSC: $T_{g}=121.2^{\circ} \mathrm{C}$.

2.8. Characterization. ${ }^{1} \mathrm{H}$ NMR spectroscopy was obtained on a JEOL JNM-ECA300 (300 MHz) or JEOL JNM-ECA400 $(400 \mathrm{MHz})$ NMR spectrometer. FT-IR spectra were collected on a Nicolet 560-IR spectrometer. The molecular weights and molecular weight distributions of the polymers were measured on a gel permeation chromatographic (GPC) instrument which is equipped with a column (PLgel $5 \mu \mathrm{m}$ MixedD) and a refractive index detector (Wyatt Optilab rEX). The temperatures during the measurements were maintained at $35^{\circ} \mathrm{C}$ and the molecular weights of the polymers were calibrated with polystyrene as standards. Chromatographic THF was used as the eluent agent and the flow rate was controlled to be $1.0 \mathrm{~mL} / \mathrm{min}$. The thermal behaviors of the polymers were performed on a TA Instrument DSC-Q100 with a heating rate of $10^{\circ} \mathrm{C} / \mathrm{min}$ from room temperature to $180^{\circ} \mathrm{C}$ and in a nitrogen atmosphere. The UV-vis spectra of the samples were measured in solution by using a Persee TU-1810SPC UV-vis spectrophotometer, the concentrations of the samples under the concentration of $0.02 \mathrm{mg} / \mathrm{mL}$ were obtained by dissolving the corresponding samples in THF 
(HP). Dielectric measurements of the azo polymers were carried out by a TH 2819A precision LCR meter. The films of the polymers were firstly obtained by casting the DMF solution of the corresponding polymer on the copper foil and then dried in an oven with the procedure of $80^{\circ} \mathrm{C}$ for $1 \mathrm{~h}, 100^{\circ} \mathrm{C}$ for $1 \mathrm{~h}, 120^{\circ} \mathrm{C}$ for $1 \mathrm{~h}$, and $160^{\circ} \mathrm{C}$ for $2 \mathrm{~h}$. Then, a simple parallelplate capacitor was fabricated by putting another copper foil on the surface of the polymeric film. The copper foils at both side of the polymeric film were used as the electrodes and the dielectric constant and dielectric loss of the samples were measured at temperature from $100 \mathrm{~Hz}$ to $200 \mathrm{kHz}$.

\section{Result and Discussion}

In this study, the relationship between the structure and the dielectric properties of the azo polymers was studied. Epoxybased azo polymers with strong push-pull azo chromophores (PAZ-ET, PAZ-CN, PAZ-NT, and PAZ-TZ) were synthesized from the precursor (PAZ) by azo-coupling reaction [44]. The synthetic route and chemical structure of these polymers are given in Figure 1. The precursor PAZ was synthesized through the condensation polymerization between bisphenol A diglycidyl ether and aniline. According to the GPC results, the number-average molecular weight of PAZ is $2.47 \times 10^{4}$ and the polydispersity index is 1.69 . PAZ shows good solubility in polar organic solvents such as tetrahydrofuran, $N, N$ dimethylformamide, and N,N-dimethylacetamide, which is critical for the subsequent azo-coupling reaction. $T_{g}$ of PAZ is $89.8^{\circ} \mathrm{C}$, which is determined by DSC.

The azo polymers (PAZ-ET, PAZ-CN, PAZ-NT, and PAZTZ) with strong push-pull azo chromophores were then prepared by the azo-coupling reaction between the precursor PAZ and diazonium salts of 4-aminobenzoic acid ethyl ester, 4-aminobenzonitrile, 4-nitroaniline, and 2-amino-5nitrothiazole at $0^{\circ} \mathrm{C}$ in a polar organic solvent such as DMF. The diazonium salts were obtained by adding the solution of sodium nitrite into the acidic aqueous solution of the corresponding amino derivatives or putting the amino derivatives directly into the nitrososulfuric acid at $0^{\circ} \mathrm{C}$. The azo-coupling reaction enables introducing various azo chromophores at the final stages of the synthetic route with high yield. As the precursor is the same and excessive diazonium salts were used in the reaction, the only differences between these azo polymers are the azo chromophores linked on the backbone. The azo polymers with strong push-pull azo chromophores are named as PAZ-X, where $\mathrm{X}$ is the abbreviations to make the distinction for the different electron-withdrawing groups.

Figure 2 shows the ${ }^{1} \mathrm{H}$ NMR spectra of the precursor and the azo polymers with assignments. For the ${ }^{1} \mathrm{H}$ NMR spectrum of PAZ, the resonance signal at $6.54 \mathrm{ppm}$ is coming from the proton $j$ which is on the para position of the benzene ring connected to the nitrogen, while the proton $i$ on the ortho position of the benzene ring connected to the nitrogen shows a resonance peak at $6.72 \mathrm{ppm}$. The resonance signals at 5.27 and $5.18 \mathrm{ppm}$ are resulting from the protons on hydroxyl groups. After the azo-coupling reaction, PAZET, for example, the resonance signal at $6.54 \mathrm{ppm}$ disappears completely indicating the $100 \%$ reaction of the PAZ. In addition, the resonance signals located at 8.06 and $7.82 \mathrm{ppm}$ are coming from the protons on the benzene ring of the azobenzene unit ( $k$ and $j$ ). What is more, resonance peaks of the protons on the benzene ring of the azobenzene unit ( $h$ and i) shift to the low field due to the formation of the azobenzene unit. The new resonance peaks at $4.30(l)$ and $1.30(m)$ ppm are coming from the methylene and methyl group connected to the ester. For the other azo polymers, the resonance peaks can also be correspondingly assigned which means that the azo polymers are successfully prepared (Figure 2).

The azo polymers were also characterized by FT-IR. In comparing with the FT-IR spectrum of PAZ, a new absorption peak at around $1385 \mathrm{~cm}^{-1}$ is observed for all of the azo polymers. This new absorption peak is attributed to the symmetrical stretching vibration of the azo group $(-\mathrm{N}=\mathrm{N}$ ) [47] which confirms the preparation of the azo polymers. The molecular weights and molecular weight distributions of the polymers were measured by using GPC. The numberaverage molecular weights of the azo polymers are $3.16 \times 10^{4}$, $2.96 \times 10^{4}, 2.91 \times 10^{4}$, and $3.01 \times 10^{4}$ for PAZ-ET, PAZ-CN, PAZ-NT, and PAZ-TZ, respectively, which are higher than that of the precursor PAZ. In addition, the molecular weight distributions of the azo polymers are also higher than that of the precursor. The thermal properties of the azo polymers were obtained by using the DSC measurement. Figure 3 shows the DSC curves of the precursor PAZ and the azo polymers PAZ-X. $T_{g}$ of PAZ is $89.8^{\circ} \mathrm{C}$. After the azo-coupling reaction, $T_{g}$ of the azo polymers increases and is 112.7, 120.5, 124.8 , and $138.7^{\circ} \mathrm{C}$ for PAZ-ET, PAZ-CN, PAZ-NT, and PAZTZ respectively. The increment of $T_{g}$ of the azo polymers is due to the formation of the azobenzene groups and the increasing of the number-average molecular weights of the samples after the azo-coupling reaction.

The UV-vis spectra of the solution of the azo polymers are shown in Figure 4. The concentrations of the solution of the samples are $0.02 \mathrm{mg} / \mathrm{mL}$ by dissolving the corresponding solid samples in THF (HP) which is a common solvent for the azobenzene and its derivatives. In comparing with the spectrum of PAZ which shows a weak absorption around $300 \mathrm{~nm}$, the azo polymers show a strong absorption in the visible region and the color of the azo polymers ranges from red to blue. This strong absorption is contributed to azobenzene which also confirms the successfully fabrication of the azo polymers. Azo chromophores are usually classified into azobenzene type, aminoazobenzene type as well as pseudostilbene type based on the spectral feature and isomerization behavior of them [34]. The pseudostilbene type azo chromophores, also known as push-pull type azo chromophores, contain strong electron-donating/electronwithdrawing substituents at the 4 and $4^{\prime}$ positions of the azobenzene moieties which results in the strong absorption bands in the visible light region. According to Figure 4, the position of the absorption band of the azo polymers is 

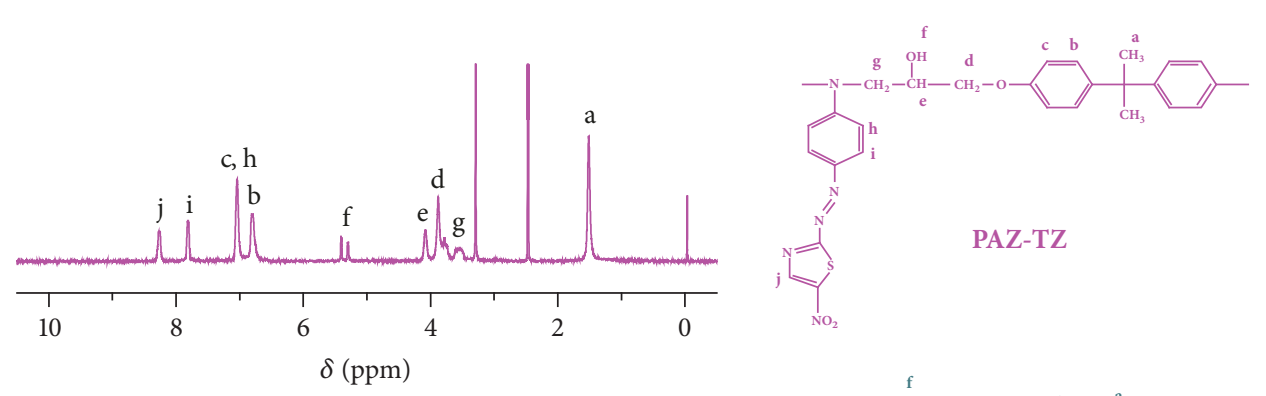

— PAZ-TZ
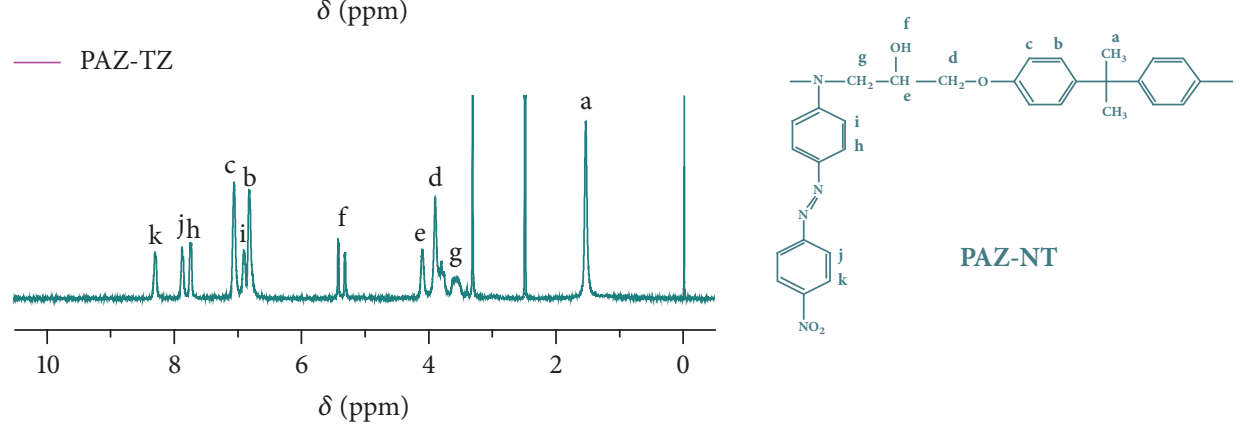

— PAZ-NT
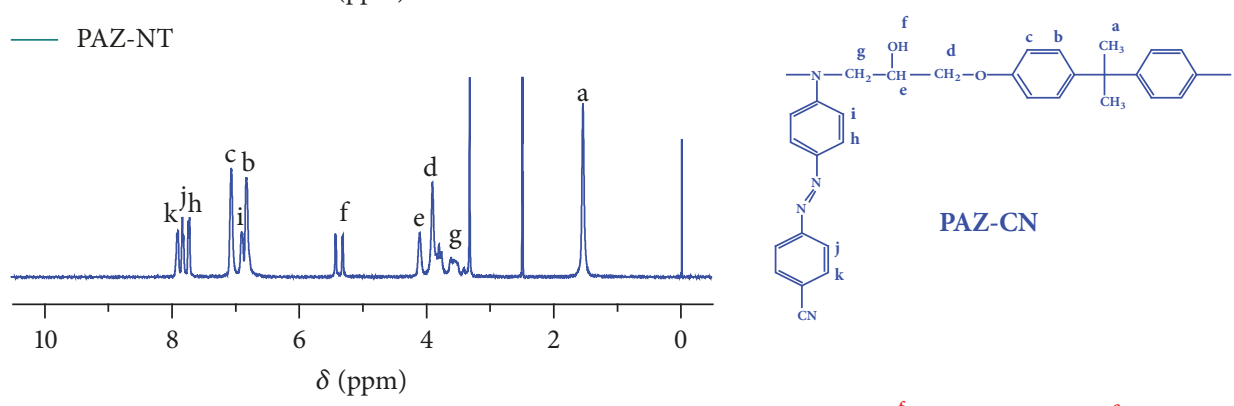

— PAZ-CN
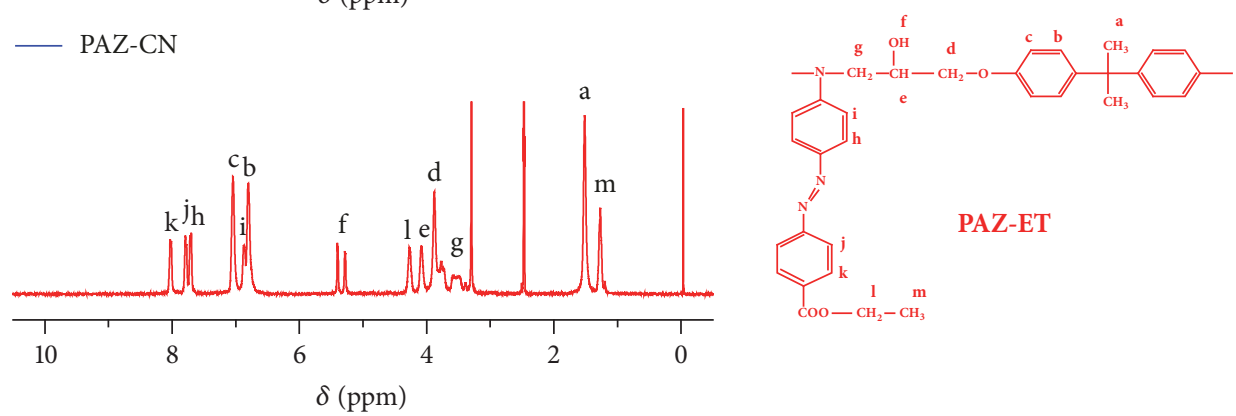

— PAZ-ET
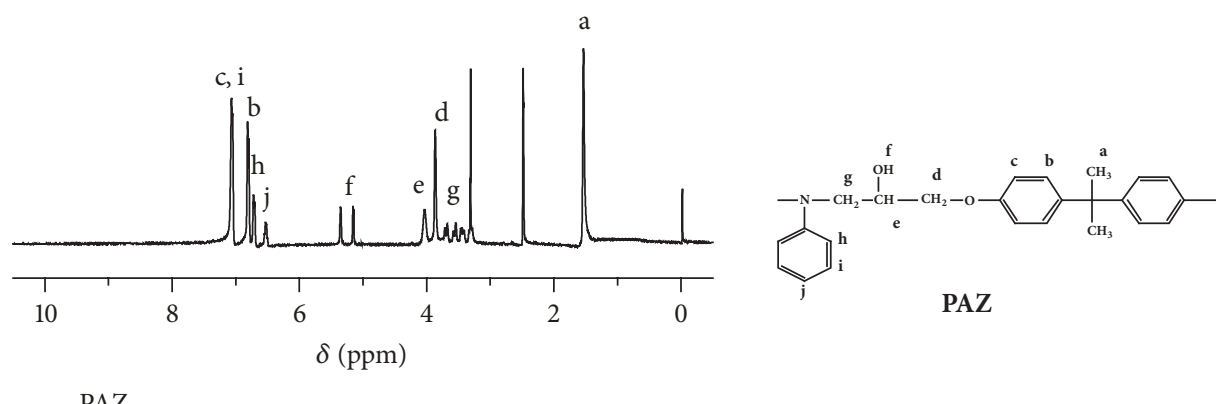

PAZ

FIGURE 2: ${ }^{1} \mathrm{H}$ NMR spectra the precursor and the azo polymers. 


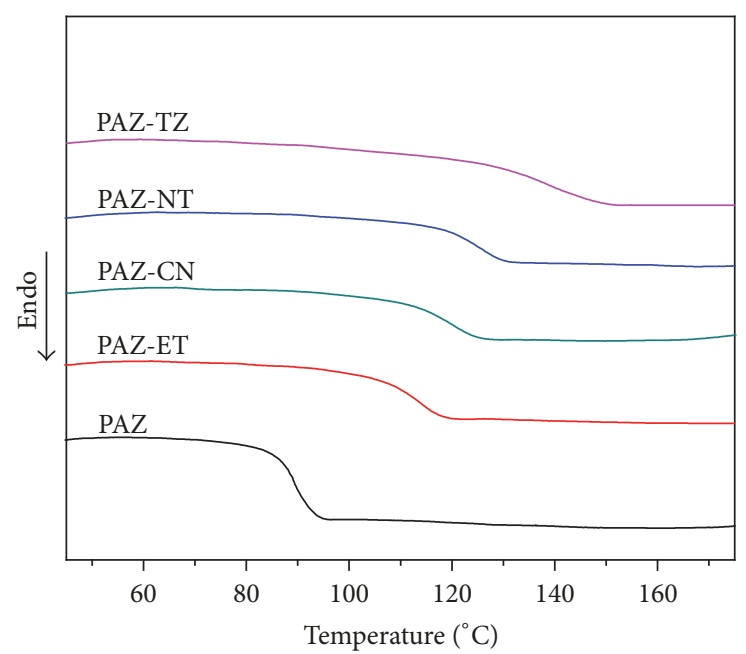

FIGURE 3: DSC curves of the polymers obtained from the second heating scan.

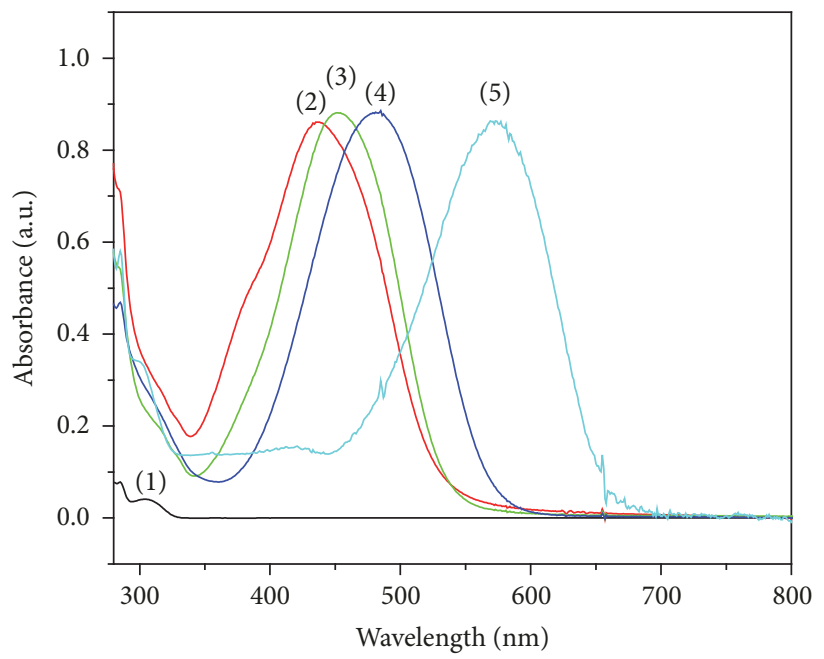

Figure 4: UV-vis spectra of the THF solution $(0.02 \mathrm{mg} / \mathrm{mL})$ of the polymers. Curve (1): PAZ, curve (2): PAZ-ET, curve (3): PAZ-CN, curve (4): PAZ-NT, and curve (5): PAZ-TZ.

determined by the electron-withdrawing group on the $4^{\prime}$ positions of azobenzene moieties. The location of the max absorption band $\left(\lambda_{\max }\right)$ of the azo polymers is $438,452,482$, and $572 \mathrm{~nm}$ for PAZ-ET, PAZ-CN, PAZ-NT, and PAZ-TZ, respectively. As the azo polymers are made from the same precursor PAZ and have the same electron-donating group on the azobenzene moiety, the red-shift of $\lambda_{\max }$ indicates the polarity of the electron-withdrawing group on the $4^{\prime}$ position of the azobenzene becomes stronger.

The dielectric constant and dielectric loss of the azo polymers and the precursor were measured in the frequency range of $100 \mathrm{~Hz}-200 \mathrm{kHz}$. For high performance polymers such as PEN, the dielectric constant, and dielectric loss can be easily measured by using the films of PEN whose surfaces were coated with a thin layer of conductive silver paste to form a plate capacitor $[21,22]$. However, as the free standing films of the precursor and the azo polymers cannot be obtained resulting from their poor mechanical property, the samples were firstly cast on the copper foil, and then a simple parallelplate capacitor was fabricated by putting another copper foil on the surface of the polymeric film. The copper foils at both sides of the polymeric film were used as the electrodes for the measurement of the dielectric constant and dielectric loss. The dielectric constant and dielectric loss of the azo polymers are shown in Figures 5(a) and 5(b). As shown in Figure 5(a), the dielectric constant of the samples decreases slightly with the increasing of measuring frequency. This decrement of the dielectric constant with changing frequency is caused by the effect of the polarization relaxation [21]. The dielectric constant of PAZ is 3.1 at $1 \mathrm{kHz}$. Due to the existence of the azo chromophores, the dielectric constant of the azo polymers increases compared with that of the precursor. In 


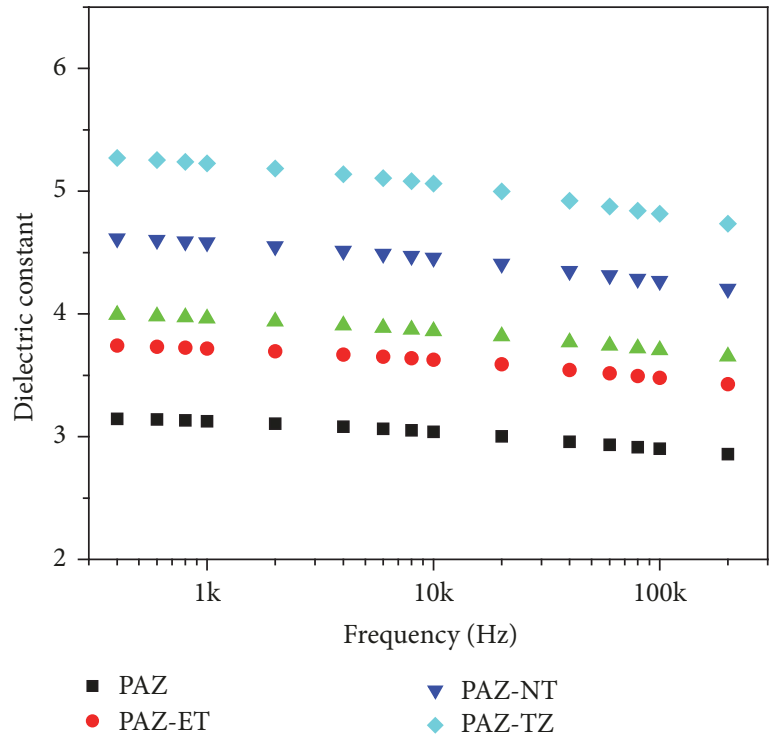

(a)

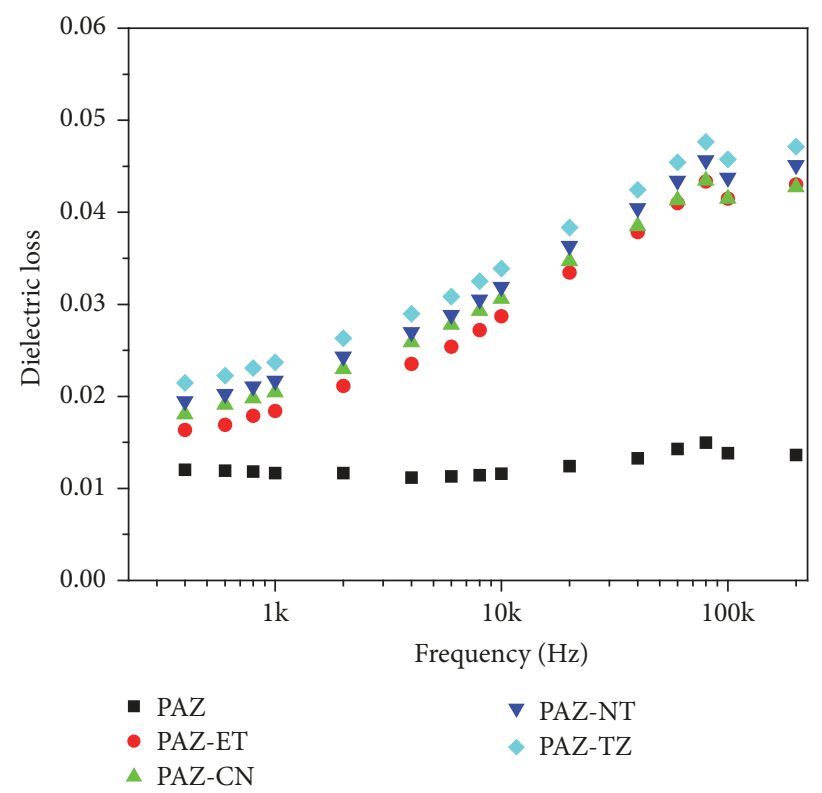

(b)

FiguRE 5: Dielectric constant (a) and dielectric loss (b) of the precursor and the azo polymers.

particular, the dielectric constant of PAZ-ET, PAZ-CN, PAZNT, and PAZ-TZ is 3.7, 4.0, 4.6, and 5.2 at $1 \mathrm{kHz}$, respectively. In addition, the increase of dielectric constant from PAZET to PAZ-TZ would be due to the fact that the electronwithdrawing group on the azobenzene of PAZ-TZ is the strongest. The dielectric loss of the azo polymers is also higher than that of the precursor due to the azo moieties. In addition, as the movement of the polar azobenzene is much easier than the main-chain of the polymers, the dielectric loss increases with the increasing of the frequency. What is more, the dielectric loss increases from PAZ-ET to PAZ-TZ as that of the dielectric constant.

After the study between the structure and the dielectric properties of the azo polymers, the contents of the azo chromophore on the dielectric properties of azo polymers were further studied. Due to the high efficiency of the azocoupling reaction, the precursor PAZ was $100 \%$ reacted to form the azo polymers (PAZ-ET, PAZ-CN, PAZ-NT, and PAZ-TZ) by using excessive diazonium salts, which was confirmed by the ${ }^{1} \mathrm{H}$ NMR spectra. On the other hand, a random copolymer composed of the azo polymer and the precursor would be obtained if inadequate diazonium salt is used. Herein, by using the diazonium salt of the 4nitroaniline as typical example, PAZ-NT-PAZ which can be seen as the random copolymer of PAZ-NT and PAZ was similarly prepared as mentioned for PAZ-NT. However, only $30 \%$ of the diazonium salt as preparing PAZ-NT was added to the PAZ solution when preparing PAZ-NT-PAZ. Figure 6 shows the ${ }^{1} \mathrm{H}$ NMR spectra of PAZ, PAZ-NT-PAZ, and PAZNT. In comparing with the ${ }^{1} \mathrm{H}$ NMR spectrum of PAZNT, the ${ }^{1} \mathrm{H}$ NMR spectrum of PAZ-NT-PAZ also shows the resonances of the azo chromophore as located at 8.34, 7.89, 7.74 , and $6.90 \mathrm{ppm}$. However, the existence of the resonance peaks at 6.73 and $6.54 \mathrm{ppm}$ indicates the incomplete reaction of the PAZ. In addition, the resonances of the proton from the hydroxyl groups also show the superposition of PAZ and PAZ-NT. According to the integral area of the resonances at 5.40 and $5.18 \mathrm{ppm}$, it can be calculated that PAZ: PAZ-NT = $6: 4$ in PAZ-NT-PAZ.

The FT-IR spectrum of PAZ-NT-PAZ also shows the absorption peak of the symmetrical stretching vibration of the azo group $\left(-\mathrm{N}=\mathrm{N}-, 1384 \mathrm{~cm}^{-1}\right)$ which confirms the existence of azo chromophores in PAZ-NT-PAZ. Figure 7 shows the UV-vis spectra of PAZ, PAZ-NT-PAZ, and PAZ$\mathrm{NT}$ in THF at $0.02 \mathrm{mg} / \mathrm{mL}$. In comparing with the UV-vis spectrum of PAZ-NT (curve (3)), the UV-vis spectrum of PAZ-NT-PAZ (curve (2)) shows the same max absorption band at $482 \mathrm{~nm}$. This result indicates the existence of the same azo chromophores in PAZ-NT-PAZ and PAZ-NT. In addition, the intensity of the max absorption band of PAZNT-PAZ is about 0.4 to that of the PAZ-NT, the same as the result of the ${ }^{1} \mathrm{H}$ NMR spectra. Combining the ${ }^{1} \mathrm{H}$ NMR spectra and UV-vis spectra, it can be concluded that the ratio of the azo chromophores in PAZ-NT-PAZ with that in PAZNT is 0.4 .

The dielectric constant and dielectric loss of PAZNT-PAZ were also measured in the frequency range of $100 \mathrm{~Hz}-200 \mathrm{kHz}$. As shown in Figure 8, the dielectric constant of PAZ-NT-PAZ is 4.1 at $1 \mathrm{kHz}$ which is between that of the PAZ and PAZ-NT. This is because that the content of the azo chromophores which contributes to the increases of the 

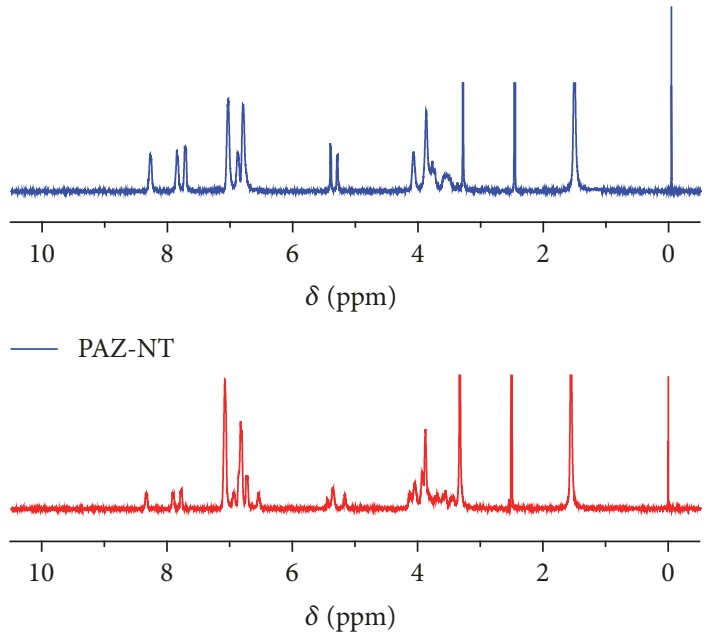

- PAZ-NT-PAZ

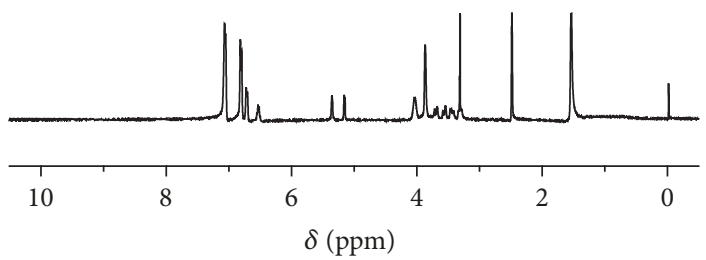

PAZ

Figure 6: ${ }^{1} \mathrm{H}$ NMR spectra of the PAZ, PAZ-NT, and PAZ-NT-PAZ.

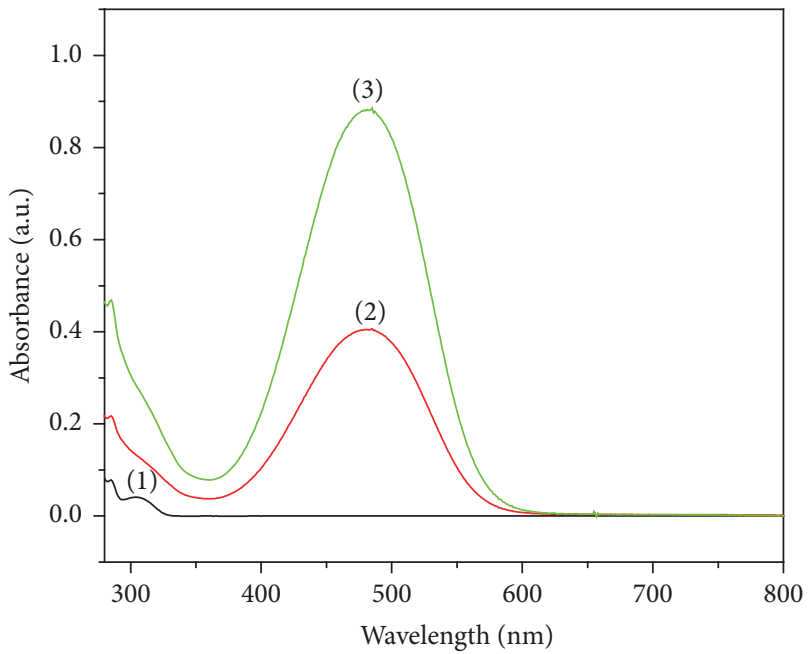

FIGURE 7: UV-vis spectra of the THF solution $(0.02 \mathrm{mg} / \mathrm{mL})$ of the polymers. Curve (1): PAZ, curve (2): PAZ-NT-PAZ, and curve (3): PAZ-NT.

dielectric constant is 0.4 to that of in PAZ-NT. As a result, it can be concluded that the dielectric constant of this kind of azo polymer can be controlled by changing the content of azo chromophores during the preparation process. The dielectric loss of PAZ-NT-PAZ is similar to that of PAZ-NT. However, as the content of azo chromophores is less, the dielectric loss of PAZ-NT-PAZ is lower than that of PAZ-NT at all the tested frequencies.

\section{Conclusions}

In summary, a series of epoxy-based azo polymers with different substituents at $4^{\prime}$-positions of the azobenzene units were synthesized through the azo-coupling reaction. The ${ }^{1} \mathrm{H}$ NMR spectra indicated the successful preparation of the azo polymers and the UV-vis spectra showed that the max absorption band of the azo polymers red-shifts with the increase of the electron-withdrawing ability of the groups at $4^{\prime}$-positions of the azobenzene unit. The dielectric properties of the azo polymers were obtained by pasting two copper foils which were used as the electrodes during the measurement at both sides of the polymeric film. In comparing with the precursor PAZ, the dielectric constant of the azo polymers increased obviously due to the large dipole moments of the azo chromophore. In addition, the dielectric constant of the azo polymers increased with the increase of the polarity of the azo chromophores and was as high as 5.2 for PAZ-TZ at $1 \mathrm{kHz}$. A random copolymer PAZ-NT-PAZ composed of PAZ-NT and PAZ was similarly prepared to investigate the content of the azo chromophores on the dielectric properties of the azo polymers. The dielectric constant of PAZ-NT-PAZ was 4.1 at $1 \mathrm{kHz}$ which is between that of PAZ and PAZ-NT. The results showed that the dielectric properties of this kind of azo polymers can be controlled by changing the structures 


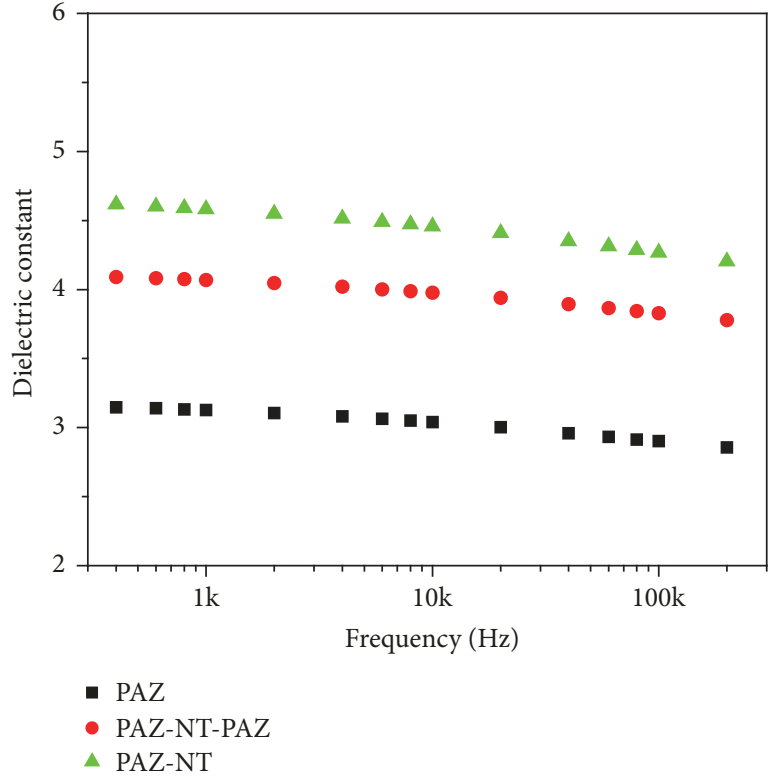

(a)

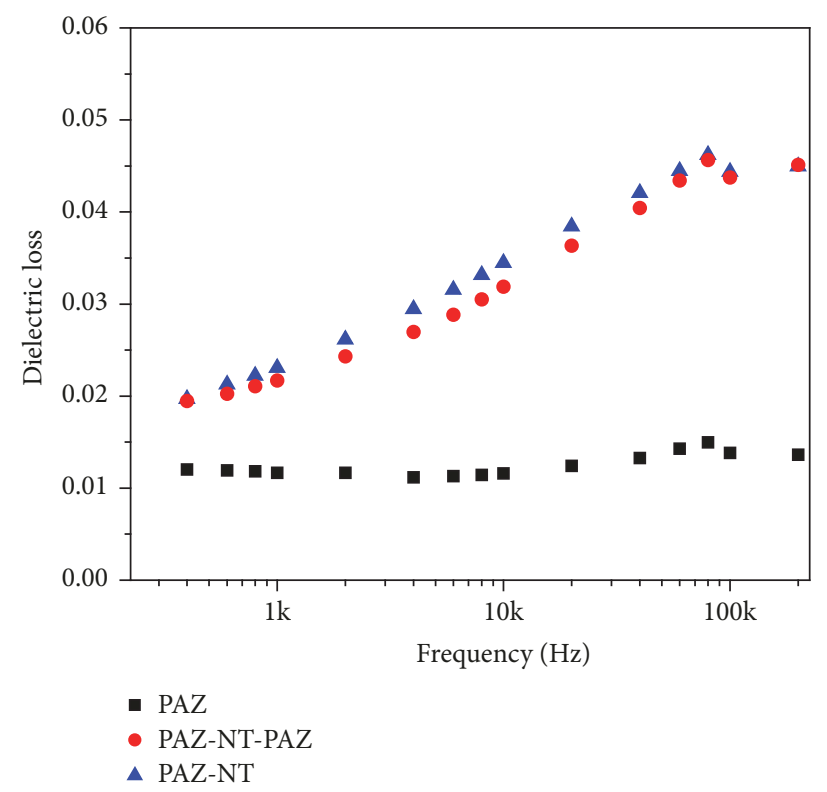

(b)

FIgURE 8: Dielectric constant (a) and dielectric loss (b) of the PAZ, PAZ-NT, and PAZ-NT-PAZ.

and contents of azo chromophores during the preparation process.

\section{Conflicts of Interest}

The authors declare that there are no conflicts of interest regarding the publication of this paper.

\section{Acknowledgments}

The financial support from National Natural Science Foundation of China (51603029) is gratefully acknowledged.

\section{References}

[1] B. Chu, X. Zhou, K. Ren, B. Neese, M. Lin, and Q. Zhang, "A dielectric polymer with high electric energy density and fast discharge peed," Science, vol. 313, no. 5785, pp. 334-337, 2006.

[2] P. Brochu and Q. Pei, "Advances in dielectric elastomers for actuators and artificial muscles," Macromolecular Rapid Communications, vol. 31, no. 1, pp. 10-36, 2010.

[3] A. Wypych, I. Bobowska, M. Tracz et al., "Dielectric properties and characterisation of titanium dioxide obtained by different chemistry methods," Journal of Nanomaterials, vol. 2014, Article ID 124814, 9 pages, 2014.

[4] V. S. Puli, D. K. Pradhan, B. C. Riggs, D. B. Chrisey, and R. S. Katiyar, "Investigations on structure, ferroelectric, piezoelectric and energy storage properties of barium calcium titanate (BCT) ceramics," Journal of Alloys and Compounds, vol. 584, pp. 369373, 2014.

[5] S. Filipović, N. Obradović, J. Krstić et al., "Structural characterization and electrical properties of sintered magnesium-titanate ceramics," Journal of Alloys and Compounds, vol. 555, pp. 39-44, 2013.
[6] Y. You, X. Du, H. Mao, X. Tang, R. Wei, and X. Liu, "Synergistic enhancement of mechanical, crystalline and dielectric properties of polyarylene ether nitrile-based nanocomposites by unidirectional hot stretching-quenching," Polymer International, vol. 66, no. 8, pp. 1151-1158, 2017.

[7] Y. You, W. Han, L. Tu, Y. Wang, R. Wei, and X. Liu, "Doublelayer core/shell-structured nanoparticles in polyarylene ether nitrile-based nanocomposites as flexible dielectric materials," RSC Advances, vol. 7, no. 47, pp. 29306-29311, 2017.

[8] Y.-H. Zhang, Z.-M. Dang, J. H. Xin et al., "Dielectric properties of polyimide-mica hybrid films," Macromolecular Rapid Communications, vol. 26, no. 18, pp. 1473-1477, 2005.

[9] K. K. Kim, A. Hsu, X. Jia et al., "Synthesis and characterization of hexagonal boron nitride film as a dielectric layer for graphene devices," ACS Nano, vol. 6, no. 10, pp. 8583-8590, 2012.

[10] B. Hoex, J. J. H. Gielis, M. C. M. Van De Sanden, and W. M. M. Kessels, "On the c-Si surface passivation mechanism by the negative-charge-dielectric Al2 O3," Journal of Applied Physics, vol. 104, no. 11, Article ID 113703, 2008.

[11] R. Yang, R. Wei, K. Li, L. Tong, K. Jia, and X. Liu, "Crosslinked polyarylene ether nitrile film as flexible dielectric materials with ultrahigh thermal stability," Scientific Reports, vol. 6, Article ID 36434, 2016.

[12] R. Wei, J. Wang, H. Zhang, W. Han, and X. Liu, "Crosslinked polyarylene ether nitrile interpenetrating with zinc ion bridged graphene sheet and carbon nanotube network," Polymer, vol. 9, no. 8, p. 342, 2017.

[13] A. Kahouli, O. Gallot-Lavallée, P. Rain et al., "Structure effect of thin film polypropylene view by dielectric spectroscopy and X-ray diffraction: Application to dry type power capacitors," Journal of Applied Polymer Science, vol. 132, no. 39, Article ID 42602, 2015.

[14] Y. Wang, X. Zhou, Q. Chen, B. Chu, and Q. Zhang, "Recent development of high energy density polymers for dielectric capacitors," IEEE Transactions on Dielectrics and Electrical Insulation, vol. 17, no. 4, pp. 1036-1042, 2010. 
[15] M. F. Galikhanov, A. A. Guzhova, A. A. Efremova, and A. I. Nazmieva, "Effect of aluminum oxide coating on structural, barrier and electret properties of polyethylene terephthalate films," IEEE Transactions on Dielectrics and Electrical Insulation, vol. 22, no. 3, pp. 1492-1496, 2015.

[16] M. Sharma, M. P. Singh, C. Srivastava, G. Madras, and S. Bose, "Poly(vinylidene fluoride)-based flexible and lightweight materials for attenuating microwave radiations," ACS Applied Materials \& Interfaces, vol. 6, no. 23, pp. 21151-21160, 2014.

[17] M. R. Gadinski, C. Chanthad, K. Han, L. Dong, and Q. Wang, "Synthesis of poly(vinylidene fluoride-co-bromotrifluoroethylene) and effects of molecular defects on microstructure and dielectric properties," Polymer Chemistry, vol. 5, no. 20, pp. 59575966, 2014.

[18] K. Li, L. Tong, R. Yang, R. Wei, and X. Liu, "In-situ preparation and dielectric properties of silver-polyarylene ether nitrile nanocomposite films," Journal of Materials Science: Materials in Electronics, vol. 27, no. 5, pp. 4559-4565, 2016.

[19] Y. Zhan, X. Yang, H. Guo, J. Yang, F. Meng, and X. Liu, "Crosslinkable nitrile functionalized graphene oxide/poly(arylene ether nitrile) nanocomposite films with high mechanical strength and thermal stability," Journal of Materials Chemistry, vol. 22, no. 12, pp. 5602-5608, 2012.

[20] L. Tong, R. Wei, J. Wang, and X. Liu, "Phthalonitrile end-capped polyarylene ether nitrile nanocomposites with $\mathrm{Cu} 2+$ bridged carbon nanotube and graphene oxide network," Materials Letters, vol. 178, pp. 312-315, 2016.

[21] R. Wei, K. Li, J. Ma, H. Zhang, and X. Liu, "Improving dielectric properties of polyarylene ether nitrile with conducting polyaniline," Journal of Materials Science: Materials in Electronics, vol. 27, no. 9, pp. 9565-9571, 2016.

[22] X. Liu, S. Long, D. Luo, W. Chen, and G. Cao, "Preparation and properties of polyarylene ether nitrites/multi-walled carbon nanotubes composites," Materials Letters, vol. 62, no. 1, pp. 1922, 2008.

[23] T. Abdel-Baset, M. Elzayat, and S. Mahrous, "Characterization and optical and dielectric properties of polyvinyl chloride/silica nanocomposites films," International Journal of Polymer Science, vol. 2016, Article ID 1707018, 13 pages, 2016.

[24] Z. Wang, R. Wei, and X. Liu, "Preparation and dielectric properties of copper phthalocyanine/graphene oxide nanohybrids via in situ polymerization," Journal of Materials Science, vol. 51, no. 9, pp. 1-9, 2016.

[25] P. Jain, R. Muralidharan, J. Sedloff, X. Li, N. A. Alcantar, and J. P. Harmon, "Processing and performance of polymeric transparent conductive composites," International Journal of Polymer Science, vol. 2013, Article ID 845432, 13 pages, 2013.

[26] Z. F. Liu, K. Hashimoto, and A. Fujishima, "Photoelectrochemical information storage using an azobenzene derivative," Nature, vol. 347, no. 6294, pp. 658-660, 1990.

[27] R. Wei, X. Wang, and Y. He, "Synthesis of side-on liquid crystalline diblock copolymers through macromolecular azo coupling reaction," European Polymer Journal, vol. 69, article no. 6716, pp. 584-591, 2015.

[28] A. A. Beharry and G. A. Woolley, "Azobenzene photoswitches for biomolecules," Chemical Society Reviews, vol. 40, no. 8, pp. 4422-4437, 2011.

[29] R. Wei, J. Ma, H. Zhang, and Y. He, "Synthesis, characterization, and photo-responsive properties of Y-shaped amphiphilic azo triblock copolymer," Journal of Applied Polymer Science, vol. 133, no. 29, Article ID 43695, 2016.
[30] G. S. Kumar and D. C. Neckers, "Photochemistry of azobenzenecontaining polymers," Chemical Reviews, vol. 89, no. 8, pp. 1915$1925,1989$.

[31] S. Xie, A. Natansohn, and P. Rochon, "Recent developments in aromatic azo polymers research," Chemistry of Materials, vol. 5, no. 4, pp. 403-411, 1993.

[32] A. Natansohn and P. Rochon, "Photoinduced motions in azocontaining polymers," Chemical Reviews, vol. 102, no. 11, pp. 4139-4175, 2002.

[33] H. Yu and T. Ikeda, "Photocontrollable liquid-crystalline actuators," Advanced Materials, vol. 23, no. 19, pp. 2149-2180, 2011.

[34] R. Wei, Z. Xu, X. Liu, Y. He, and X. Wang, "Liquid-crystalline compounds containing both a strong push-pull azo chromophore and a cholesteryl unit as photoresponsive molecular glass materials," Journal of Materials Chemistry C, vol. 3, no. 41, pp. 10925-10933, 2015.

[35] Y.Zhu, Y. Zhou, and X. Wang, "Photoresponsive behavior of two well-defined azo polymers with different electron-withdrawing groups on push-pull azo chromophores," Dyes and Pigments, vol. 99, no. 1, pp. 209-219, 2013.

[36] G. Ye, D. Wang, Y. He, and X. Wang, "Nunchaku-like molecules containing both an azo chromophore and a biphenylene unit as a new type of high-sensitivity photo-storage material," Journal of Materials Chemistry, vol. 20, no. 47, pp. 10680-10687, 2010.

[37] Y. He, X. Wang, and Q. Zhou, "Epoxy-based azo polymers: synthesis, characterization and photoinduced surface-reliefgratings," Polymer Journal, vol. 43, no. 26, pp. 7325-7333, 2002.

[38] C. Hubert, C. Fiorini-Debuisschert, I. Maurin, J.-M. Nunzi, and P. Raimond, "Spontaneous patterning of hexagonal structures in an AZO-polymer using light-controlled mass transport," Advanced Materials, vol. 14, no. 10, pp. 729-732, 2002.

[39] H. Finkelmann, E. Nishikawa, G. G. Pereira et al., "A new optomechanical effect in solids," Physical Review Letters, vol. 87, no. 1, 2001, 015501.

[40] M.-H. Li, P. Keller, B. Li, X. Wang, and M. Brunet, "Light-driven side-on nematic elastomer actuators," Advanced Materials, vol. 15, no. 7-8, pp. 569-572, 2003.

[41] Y. L. Yu, M. Nakano, and T. Ikeda, "Photomechanics: directed bending of a polymer film by light," Nature, vol. 425, no. 6954, p. 145, 2003.

[42] D. Lei, J. Runt, A. Safari, and R. E. Newnham, "Dielectric properties of azo dye-poly(methyl methacrylate) mixtures," Macromolecules, vol. 20, no. 8, pp. 1797-1801, 1987.

[43] X. Wang, S. Balasubramanian, J. Kumar, S. K. Tripathy, and L. Li, "Azo chromophore-functionalized polyelectrolytes. 1. synthesis, characterization, and photoprocessing," Chemistry of Materials, vol. 10, no. 6, pp. 1546-1553, 1998.

[44] X. Wang, K. Yang, J. Kumar et al., "Heteroaromatic chromophore functionalized epoxy-based nonlinear optical polymers," Macromolecules, vol. 31, no. 13, pp. 4126-4134, 1998.

[45] J. Wang, Y. Zhou, X. Wang, and Y. He, "Synthesis of Y-shaped amphiphilic copolymers by macromolecular azo coupling reaction," RSC Advances, vol. 5, no. 13, pp. 9476-9481, 2015.

[46] Y. He, W. He, D. Liu, T. Gu, R. Wei, and X. Wang, "Synthesis of block copolymers via the combination of RAFT and a macromolecular azo coupling reaction," Polymer Chemistry, vol. 4, no. 2, pp. 402-406, 2013.

[47] Y. Zhu, Y. Zhou, Z. Chen, R. Lin, and X. Wang, "Photoresponsive diblock copolymers bearing strong push-pull azo chromophores and cholesteryl groups," Polymer, vol. 53, no. 16, pp. 3566-3576, 2012. 


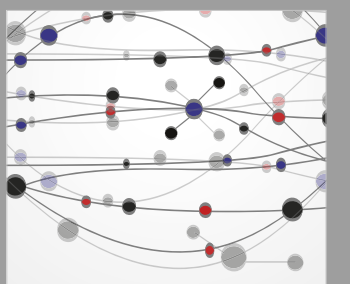

The Scientific World Journal
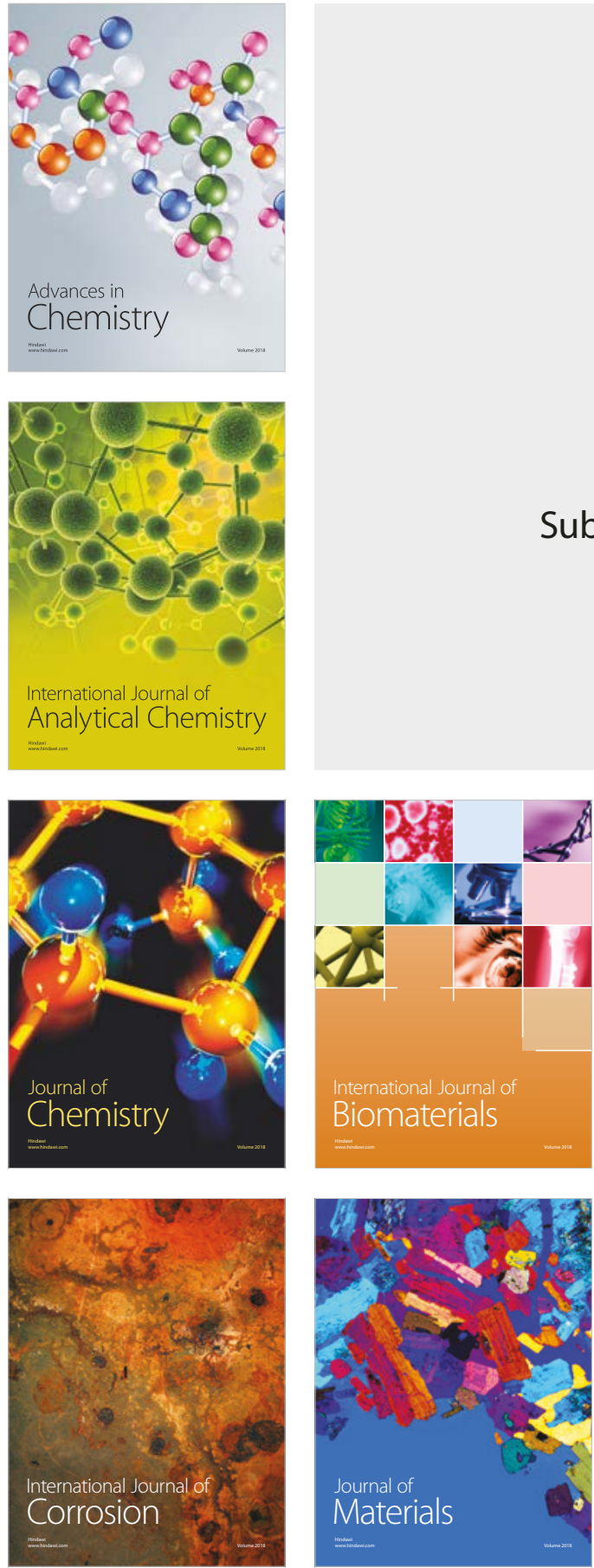

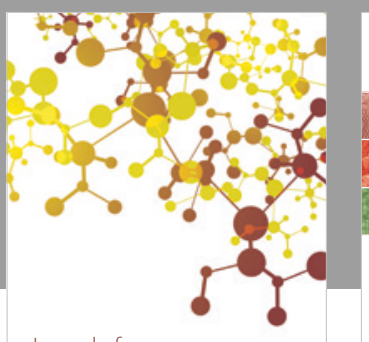

Journal of

Applied Chemistry
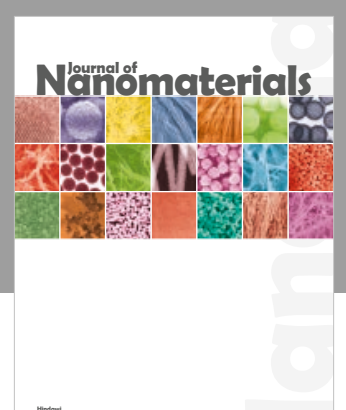

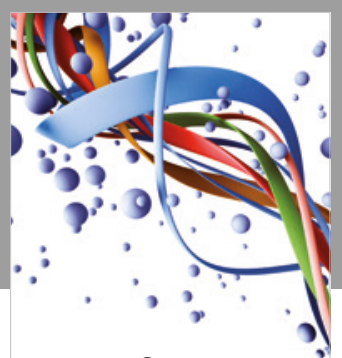

Scientifica

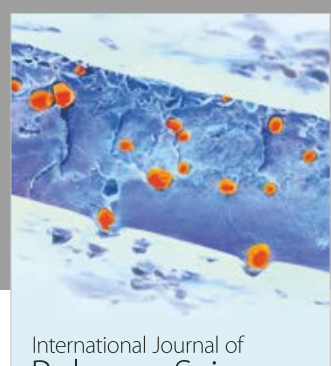

Polymer Science

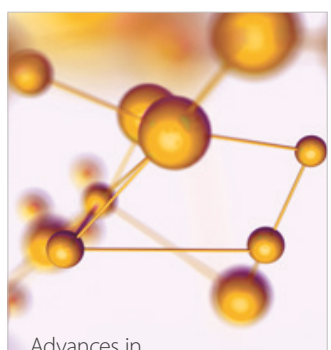

Physical Chemistry
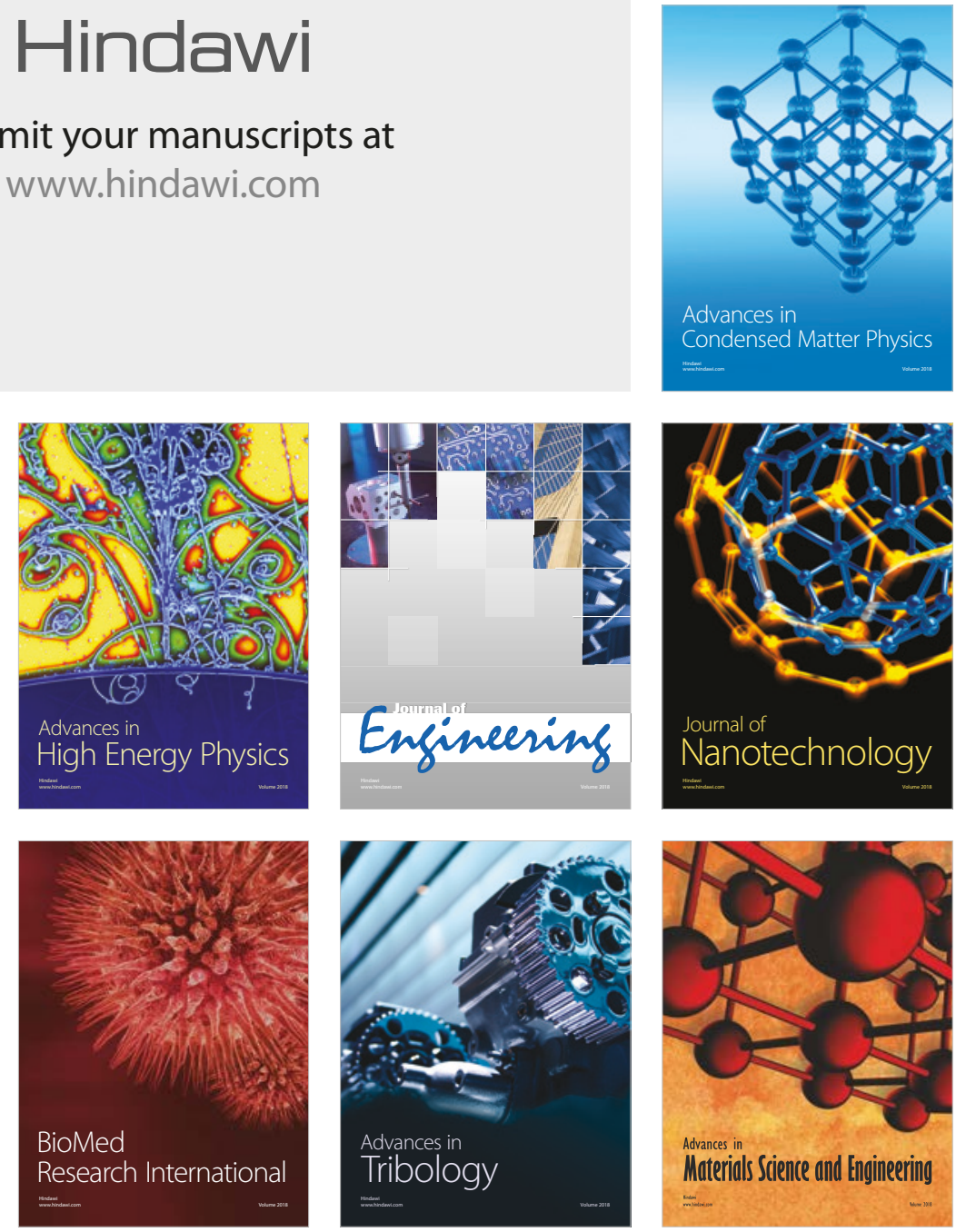